Ansgar Frank

\title{
Formwechsel im Binnenmarkt
}

\author{
Die grenzüberschreitende Umwandlung von Gesellschaften in Europa
}

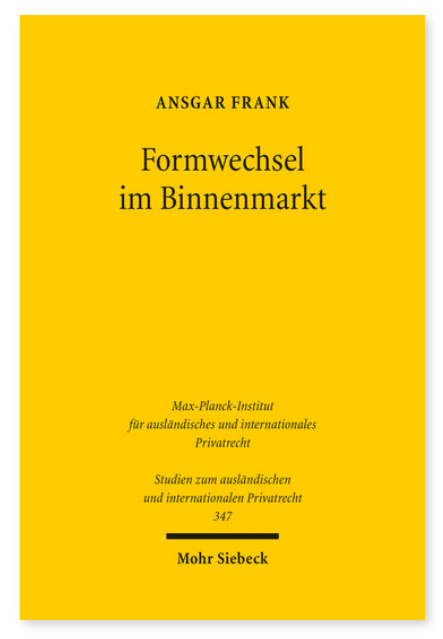

2016. XXIII, 355 Seiten. StudIPR 347

ISBN 978-3-16-154487-3

DOI 10.1628/978-3-16-154487-3

eBook PDF 79,00€

ISBN 978-3-16-154333-3

fadengeheftete Broschur 79,00€
Bei einem Formwechsel handelt es sich um einen Vorgang, durch welchen eine Gesellschaft unter Beibehaltung ihrer rechtlichen Identität ihre Rechtsform ändert. Nach der jüngsten Rechtsprechung des Europäischen Gerichtshofs sollen grenzüberschreitende Formwechsel - also Umwandlungen zwischen Rechtsformen unterschiedlicher Jurisdiktionen - in Europa zulässig sein. Eine einheitliche normative Rechtsgrundlage hierfür besteht in den Rechtsordnungen der Mitgliedstaaten jedoch nicht. In einer Grundlagenstudie unter Berücksichtigung des deutschen und des englischen Rechts widmet sich Ansgar Frank diesem praktisch überaus bedeutsamen Thema, dessen Komplexität nicht zuletzt daraus resultiert, dass es mit dem europäischen Primärrecht, dem Internationalen Privatrecht und dem materiellen Gesellschafts- und Umwandlungsrecht durch drei Rechtsgebiete beeinflusst wird, die zum Teil unterschiedliche Interessen verfolgen.

Ansgar Frank Geboren 1983; Studium der Politikwissenschaften und der Rechtswissenschaften an der Ludwig-MaximiliansUniversität München; 2010 Erste Juristische Prüfung; Rechtsreferendariat in Freiburg; 2012 Zweite Juristische Staatsprüfung; 2015 Promotion; seit 2014 Rechtsanwalt in Berlin.

Jetzt bestellen:

https://mohrsiebeck.com/buch/formwechsel-im-binnenmarkt-9783161544873?no_cache=1

order@mohrsiebeck.com

Telefon: +49 (0)7071-923-17

Telefax: +49 (0)7071-51104 